Editorial

\title{
Digital servitization: Crossing the perspectives of digitization and servitization
}

\section{A B S T R A C T}

For over three decades now, several product companies around the world have been undertaking servitization paths. They have been devoting growing and substantial efforts to expand their service business. Expanding the service business in addition to their traditional core product business secures long-term growth and strengthens competitive advantages in business-to-business marketplaces. Recently, service business expansion has taken up many of the new digital technologies offered through the digital transformation. Thus, the servitization literature has progressed toward a dialogue on digital servitization . Against this background, the present article introduces the reader to this special issue. It first recalls key aspects of the emerging digital servitization discussion, and then depicts, through illustrative case studies, the growth paths utilized by industrial product companies when they take advantage of the digital servitization process. After discussing how the articles included in this special issue advance the literature, the article develops a number of directions for future research on digital servitization.

\section{Introduction}

For over three decades product companies around the world, from small-sized to global corporations, from component suppliers to original equipment manufacturers, have been devoting growing and substantial efforts to expand their service business (Baines, Lightfoot, Benedettini, \& Kay, 2009; Gebauer, 2008; Kowalkowski, Gebauer, \& Oliva, 2017). These efforts have been conceptualized through various different notions (e.g. hybrid offerings, integrated solutions, service infusion, transition from products to services, service-led growth, service-oriented business models) (Rapaccini \& Visintin, 2015). Among these many terms, servitization is the most widely used to describe the phenomenon of product companies turning increasingly toward service-business, in order to achieve growth and competitive advantages (Baines et al., 2017). Research on and around servitization has encountered increased interest over the last two decades, and the recent debate surrounding digital servitization highlights the growing attention being paid to the convergence of two important research domains, namely servitization and digitalization (Vendrell-Herrero, Bustinza, Parry, \& Georgantzis, 2017).

Against this background, the purpose of this special issue of Industrial Marketing Management is to provide an academic perspective on digital servitization in business markets, and to advance knowledge in this area. The present article introduces the reader to this special issue. We first recall key aspects of digital servitization, after which we demonstrate what digital servitization means, as the combination of servitization and digitalization, showing examples of different growth trajectories. In the third part of our article, we introduce the reader to the other articles included in this special issue of Industrial Marketing Management and discuss how they advance literature on digital servitization. Finally, we combine the managerial and research insights gained from the papers in this special issue to develop a number of directions for future research on this topic.

\section{Digital servitization}

Digital servitization describes the convergence of servitization and digitalization. The first phenomenon - Servitization - is predominantly related to the transformation from products to services, and has been investigated for decades. As customer expectations have been shifting from buying/consuming products to adopting sophisticated solutions that solve contextual problems and create value-in-use, customers in both consumer and business markets expect to receive advanced services and improved customer experience through dealing with such products (Story, Raddats, Burton, Zolkiewski, \& Baines, 2017). Instead of paying for products, business customers increasingly want to receive only the value inherently offered by the product use, thus consuming it as a service (Cusumano, Kahl, \& Suarez, 2015; Tukker, 2004). Servitization entails a transformation journey, which is deeply rooted in the product company's value-generating mechanisms (Baines et al., 2007; Teece, 2010) and acts as a manifestation of the firm's business strategy (Cortimiglia, Ghezzi, \& Frank, 2016; Kastalli \& Van Looy, 2013).

A second recent trend affecting product companies is that of Digitalization, broadly defined as "the adoption or increase in use of digital or computer technology by an organization, industry, country, etc." (OED online, 2020). Enabling new ways of value creation, the progressive and pervasive adoption and integration of digital technologies is exerting a tremendous impact on industries, society and economy (Porter \& Heppelmann, 2014, 2015; Ross, Beath, \& Mocker, 2019).

This is well illustrated by digital pioneers such as Google, Apple, Facebook, Amazon, and Microsoft - the so-called "Frightful Five" (Manjoo, 2017) - which summarizes the impact of new digital businesses on the world economy and society. Compared to industrial giants founded many decades ago (e.g. Bosch in 1886, Caterpillar 1925, JohnDeer 1868, Siemens 1966, General Electric 1890, Hitachi 1909), the abovementioned pioneers have emerged recently - the newest of the five, Facebook, was founded in 2004. Benefiting from the rapid growth of the internet economy and social media, these firms have scaled up their revenue enormously by continually branching into new areas. These include, for instance, cloud computing services (e.g. AWS, Google Drive, Microsoft Azure), artificial intelligence (e.g. Microsoft ML, Google TensorFlow, Facebook Pytorch), self-driving vehicles (e.g. Apple and Google Cars), platforms and marketplaces (e.g. Apple Store, 
Google Play, Microsoft Store), virtual and augmented reality (e.g. Microsoft Hololens, Facebook Oculus, Google Glass). These all show how business digitalization is not associated primarily with the adoption of some specific technology, but is essentially built on their combination, in order to enable new ways of value creation in both consumer and industrial markets. The remarkably cumulative effects from the integration of breakthrough technologies is also acknowledged by current research on Industry 4.0 (Schneider, 2018), and confirmed by the strategic pathways that large industrial companies have also recently undertaken.

A notable example of business digitalization in large industrial companies is Siemens, the German industrial-diversified giant. The product-centric business of Siemens in electrification and automation accounts for around 60 billion Euros. Traditional services, such as the sales of spare parts and maintenance contracts, add a further 17 billion Euros (FY2016). Besides this combined revenue of 77 billion, Siemens generates an additional 3.3 billion Euros from digital products (e.g. software licenses), and 1 billion from digital services (e.g. remote optimization of devices to increase OEE). The digital products offering of Siemens includes software for product and process design, simulation and control (e.g. the suite NX), and leading digital platforms, such as Mindsphere or Mendix. The first is an industrial internet platform for connecting industrial equipment, collecting field data and facilitating the development of digital services such as remote monitoring and predictive maintenance. The second is a cloud environment for the low-code deployment of mobile applications. This increasingly wide offering of digital products -the result of a clear growth strategy of financial investments - since 2007 Siemens invested over 11 billion Euros in M\&A operations in the industrial software market - is key to selling digital services and boosting the digital market of Siemens. This has been reported to have grown by 12\% [CAGR] from 2015 to 2016 and the company was expecting further growth of about $8 \%$ from 2017 to 2020 . By contrast, the CAGR of the traditional products and services market was estimated at below $4 \%$ in the same period.

A basic framework underlying the key topic of this special issue is to explore digital servitization as a convergence of servitization and digitalization. This convergence is opening up new growth opportunities for producers of industrial and consumer goods, as in the Siemens case. These growth opportunities can be illustrated by a two-by-two matrix (see Figure 1), in which the horizontal axis distinguishes between product and service-growth opportunities, whereas the vertical axis depicts the growth opportunities generated by the development of physical rather than digital (strategic) assets. Servitization is then depicted by any move along the horizontal axis, when product-centric companies create increasing value by integrating more and more services into their offering, in order to address specific customer needs/ problems. The move along the vertical axis illustrates digitalization, in which revenue is increasingly generated through new digital offerings.
The figures for the Siemens business mentioned above are shown in the four quadrants of the same Figure 1.

In implementing their servitization and digitalization strategy, product companies face two paradoxes that can prevent them from achieving revenue growth through selling services and/or digital products. The servitization (service) paradox suggests that companies invest in services, but may well not earn the expected returns (Brax, 2005; Gebauer, Fleisch, \& Friedli, 2005; Neely, 2008), Similarly, the digitalization (digital) paradox suggests that investment to procure and develop digital assets have rarely been paid off yet (Gebauer, Fleisch, Lamprecht, \& Wortmann, 2020). Both paradoxes seem counterintuitive to the often enthusiastically announced opportunities in the service and digital markets. Service market opportunities are often argued to be multiple times higher than product market opportunities, due to the high installed base and product lifecycle costs. At the same time, digital market opportunities are often proclaimed as likely to reach up to a couple of trillion USD annually by 2025 .

The matrix in Figure 1 does not suggest the need for a strict distinction between product, service, and digital offerings. By contrast, companies should combine products, services and digital technologies to create digital solutions that more effectively address their customers' needs. Thus, the concept of hybrid/integrated offerings (products and services) should be extended toward digital offerings, and this also implies that research on servitization and digitalization should converge, as they are probably "two sides of the same coin" (Rust, 2004, p. x).

A question arising is: Why should companies focus on revenue growth as a main goal when it comes to digital servitization? Reducing costs through deploying digital technologies for manufacturing processes, service delivery and so on are also important. Cost improvements are certainly relevant, but they will be quickly imitated by competitors and merely give product companies a short-term cost advantage. Revenue growth means that product companies really strengthen their position in the market and utilize digital servitization to advance the current offerings. These new and often hybrid offerings allow companies to better target customers' "sweet spots" and can, therefore, lock-in customers and strengthen relationships. Once these new offerings are successful, it is very difficult for competitors to regain the lost market shares.

\section{Company examples of achieving service and digital growth}

While there is a clear argument in favour of digital servitization, the growth trajectories and implications look quite different. Figure 2 highlights selected company examples. We illustrate these here, together with further company examples, in order to supplement the case study research presented in this special issue. While these contributions reveal different pathways for digital servitization, all these illustrations highlight the revenue-growth implications.
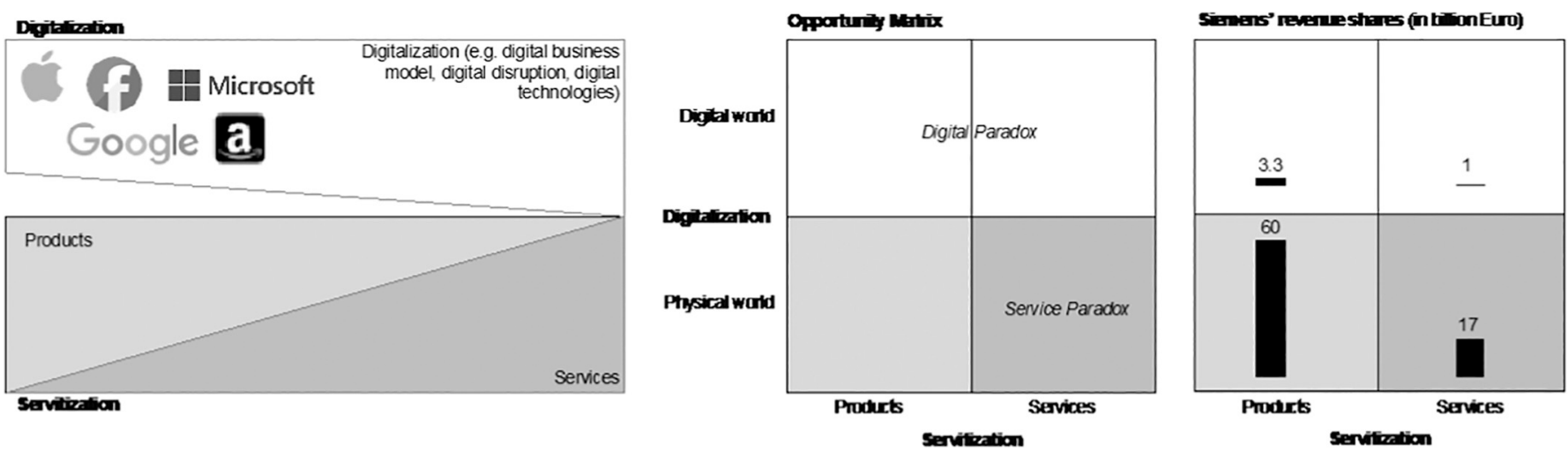

Fig. 1. Digital servitization as the convergence between servitization and digitalization. 


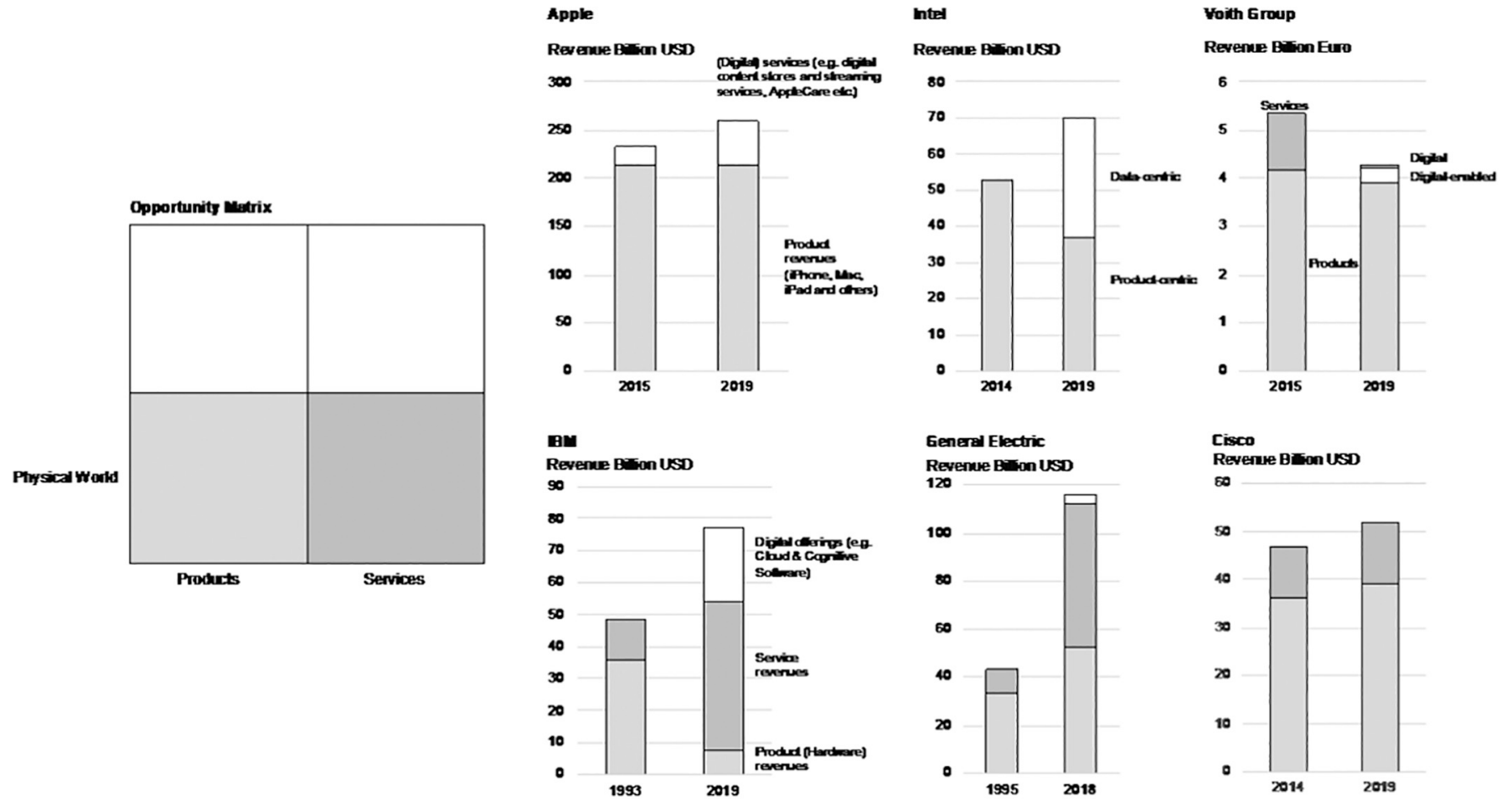

Fig. 2. Revenue structure evolution in exemplary cases.

\section{1. $I B M$}

IBM has been a key example of the transition from products to services. IBM grew its service business from $27 \%$ of revenue in 1993 to $57 \%$ in 2005. More recently, IBM $(1993,2005,2018)$ has also become a pioneer in digital growth and reports that it generates $39 \%$ of its revenue with digital products and services, with the remaining revenue generated through products $(10 \%)$, services $(49 \%)$, and other sources $(2 \%)$.

\subsection{Cisco}

Cisco has a long history of growing product and service revenue. In 2014, Cisco realized total revenue of 47.1 billion USD. Service accounted for 11 billion (23.4\%) and products for 36.1 billion USD (76.6\%). In 2019, Cisco's total revenue was 51.9 billion USD, with 12.9 billion generated through services (24.9\%) and 39.0 billion (75.1\%) through products. Besides growing product and service business, Cisco aimed at changing the revenue streams toward deferred and/or recurring revenue. Cisco designs solutions that provide customers with more financial flexibility and continuous value, and at the same time, Cisco shifts the business model to more recurring revenue streams. In 2014, these deferred (recurring) revenue streams already accounted for $29.9 \%$ of Cisco's business and increased to $35.7 \%$ in 2019 .

\subsection{Apple}

As a digital pioneer, Apple has strongly built on product revenue. The revenue structures suggest that Apple's main revenue growth between 2015 and 2019 is the result of an increase in the digital service business. Apple's product categories (iPhone, Mac, iPad, and other devices) at 213.8 billion USD accounted for $91.4 \%$ of its total revenue, and services at 19.9 billion USD for $8.6 \%$ in 2015. In 2019, digital service revenue already accounted for 46.3 billion USD (17.8\% of total revenue ( 260.2 billion USD) and product revenue for 231.2 billion USD (82.2 billion USD).

\subsection{General Electric (GE)}

By expanding the services successfully, GE has been argued to constitute a pioneer in the servitization process. In 1995, services already generated about $22 \%$ of GE's revenue, and by 2005 , services represented $36 \%$. In 2015, GE announced that it would look for new growth opportunities through digitalization, and the company projected it would increase digital revenue. Accordingly, digital revenue accounted for $2.9 \%$ ( $\$ 3.1$ billion) of the company's revenue in 2015 and $3.2 \%$ ( $\$ 3.9$ billion) of its revenue in 2018 . However, it is important to recognize that altering its core business activities trapped GE in a difficult financial situation, with significant losses in 2018 (General Electric, 1995, 2005, 2015, 2018).

\subsection{Voith Group}

Voith is a large diversified industrial group, producing equipment for the paper industry, power plants, drive and brake systems, control and automation solutions. Voith is going through a digital transformation journey with interesting implications for digital growth. Until 2015, Voith Group consisted of four strategic business units: Voith Hydro, Paper, and Turbo as well as Voith Industrial Group. It organized its service business in a separate strategic business unit. Voith Industrial Services generated $22 \%$ of total 5,345 million Euro revenue $(1,178$ million Euro). In 2015, Voith announced that it would focus its portfolio on technology and engineering expertise for the digital age, and discontinued the Voith Industrial Services Group Division. In 2016, Voith started the new unit for digital ventures, so as to facilitate the digital transformation journey and digital growth. Besides being an additional revenue stream, digitalization can enhance product and service revenue in the physical world, as it helps to differentiate existing products and services by increasing perceived customer value. Voith Group revenue remained relatively stable from $2016(4,252$ million Euro) to 2019 (4,276 million Euro). Voith started of making 13 million Euro in revenue from the digital business in 2016. To more accurately track digital business growth, Voith have been distinguishing between direct and indirect revenue since 2017. In 2019, Voith 
reported digital revenue in the form of direct revenue (60 million Euro, $1.4 \%$ of Voith's revenue) and physical revenue supported by digitalization (286 million Euro, 6.7\% of Voith's revenue) (Voith, 2018).

\subsection{Intel}

Founded in 1968, Intel became the world's most valuable semiconductor company and a typical product company. For many decades, Intel has dominated the microprocessor market (e.g. desktop personal computers, notebooks, tablets, and mobile phone). Until 2014, Intel generated its total product revenue of 52.8 billion USD from various product categories. Over the last four years, Intel has been in the midst of one of the most significant transformations in its history. It invested heavily to enter data-rich markets and redefine its value propositions, evolving from a PC-centric company with a component business into a data-centric company with an expanding portfolio of technology solutions (e.g. big data, artificial intelligence) that address customer needs across platforms, storage, connectivity, and software. This transformation is evident in changes in Intel's revenue structure from 2018, of which roughly half (70.8 billion USD) is now earned from data-centric businesses. The data-centric business accounts in fact for 33.8 billion USD, and the product-centric business for 37.0 billion USD. Intel provides customers with solutions for processing, analyzing, storing, transferring, and turning data into actionable insights.

\section{The contributions in this special issue}

In this section, we introduce the reader to the articles included in this Industrial Marketing Management Special Issue, presenting their aims and objectives and discussing how they advance knowledge on digital servitization.

The first article by Paschou, Rapaccini, Adrodegari and Saccani examines the convergence between servitization and digital technologies, offering a comprehensive review of the literature and identifying areas for future research. The authors show that the coverage of the phenomenon by scientific studies is growing rapidly, but still presents a wide range of avenues of supplementary investigation. So far, the literature has mainly focused on the role of a few isolated and specific digital technologies (above all, the Internet of Things) for the implementation of intermediate and advanced services, rather than dealing with technological bundles. As far as methodology is concerned, research has mainly adopted a qualitative approach, with casebased empirical settings, mostly investigating the automotive, industrial equipment and IT industries. The authors identify useful extensions to research on digital servitization through studying the technologies covered, their combinated effect, potential benefits and application domains, and in order to develop models and frameworks for supporting decision-making by managers and practitioners.

In the second article, Coreynen, Matthyssens, Vanderstraeten, and Witteloostuijn start from the observation that, despite the increased interest in digital technologies for servitization purposes, little is known about what drives firms towards a digital servitization strategy. Accordingly, they adopt a dynamic capabilities perspective in order to investigate whether and how the pursuit of exploitation and/or exploration is associated with firms' pursuit of digital servitization. Also acknowledging the effects of environmental contingencies like technological turbulence and competitive intensity, the authors describe and analyze empirical evidence from a quantitative investigation of 139 Belgian firms, presenting the results of a hierarchical regression analysis. Their findings show that while exploitation and exploration are individually positively associated with digital servitization, exploration "trumps" the effect of exploitation when firms pursue ambidexterity (exploration and exploitation simultaneously). The article contributes to the literature by unravelling the relationship between firms' dynamic capabilities and their environment, urging firms to adapt their strategy to an increasingly changing environment. Technological turbulence as a factor in the business environment is positively associated with digitization, regardless of the firm's level of exploration or exploitation, and competitive intensity only relates positively with servitization when firms emphasize exploration.

The third article by Paiola and Gebauer uses the Business Model Innovation lens for describing the impact of four front-end deeply interlinked technologies (IoT, Cloud computing, Big Data and Data Analytics) on firms' digital servitization strategies. The paper focuses particularly on business-to-business manufacturing firms, discussing the findings of a qualitative cross-case analysis of 25 Italian firms that show how firms with different value-chain positions can use these "IoT technologies" in order to enlarge their traditional value propositions with the offer of advanced customer-related services. The article describes both opportunities and challenges that digital servitization may present and pose to traditional manufacturers' Business Models, highlighting and characterizing the various strategic impacts that different uses of IoT technologies may have on a firm's business model elements. The authors propose a map of digital servitization that helps companies to navigate through strategic transitions caused by technologies, and underline the impact of the specific sales model as a strategic factor in shaping firms' digital servitization strategies. Three progressive levels of digital servitization complexity are identified and proposed, namely product-, process-, and outcome-oriented, which are based on an increasing use of IoT technologies and are associated with specific challenges and opportunities.

In the fourth article, Tronvoll, Sklyar, Sörhammard, and Kowalkowski start from the observation that although manufacturers increasingly look to digitalization to drive service growth, success is far from guaranteed. They therefore address the link between digitalization and servitization, adopting a discovery-oriented, theories-in-use approach in order to examine the strategic organizational shifts that underpin digital service-led growth. In-depth interviews with senior executives and managers from a global market leader reveal that product companies may simply focus too much on technology, which suggests that digital servitization requires three interconnected transformational shifts: (1) from planning to discovery, (2) from scarcity to abundance, and (3) from hierarchy to partnership. Furthermore, organizational identity, dematerialization, and collaboration play a key role in this transformation aimed at moving toward digital servitization, which requires changes in the entire network of the focal firm and requires an agile mindset.

The fifth article by Kamalaldin, Linde, Sjödin, and Parida applies the theoretical lens of the relational view theory to a study of four providercustomer relationships engaged in digital servitization. The article focuses on provider-customer relationships, addressing the knowledge gap related to how providers and customers transform their relationship to achieve benefits from digital servitization. The paper highlights four relational components that enable providers and customers to gain from digital servitization: complementary digitalization capabilities, relation-specific digital assets, digitally enabled knowledge-sharing routines, and partnership governance. It also offers a framework revealing how the four relational components evolve as the relationship progresses, offering key insights into the interdependence of activities throughout the transformation phases of provider-customer relationships in digital servitization.

The sixth article by Naik, Schroeder, Kapoor, Bigdeli and Baines moves from the observation that the literature effectively describes the uses of IoT that enable servitization, but fails to explain the processes manufacturers go through to create these outcomes. Against this backdrop, the article aims to identify such processes by using affordance theory and its core principles (affordance perception and affordance actualization) to analyze the case scenarios of six manufacturing firms, and develops a useful framework for developing a fine-grained understanding and exploitation of IoT-driven opportunities for digital servitization. Through this cross-case analysis, the study identifies three types of affordances and actions that enable manufacturers to realise 
their servitization goals from the IoT technology. This framework enables manufacturers to systematically manage the contributions from the IoT and the associated actualization efforts required to advance servitization. In addition, the study reveils the complex web of affordance dependencies that underlie the manufacturers' digital servitization, thus identifying relevant interactions between affordances.

\section{An agenda for academic inquiry on digital servitization}

Despite the growing body of research, the literature on digital servitization in business-to-business markets is still at an early stage. The articles in this special issue help to fill important gaps in our academic understanding of the convergence of servitization and digitalization that takes place in product companies. We hereafter summarize the research avenues suggested by the papers in this special issue and add further aspects that could constitute relevant research directions. We firstly follow and briefly summarize the seven research avenues described by Paschou et al. in this special issue:

i.) addressing the role of digital servitization in emerging economies;

ii.) evolving the research objectives (from exploratory to confirmatory and prescriptive), through models and frameworks that also support decision-making;

iii.) focusing the research scope on specific industry sectors and their different dynamics, moving in particular from machinery and B2B industries to consumer products (see also Naik, Schroeder, Kapoor, Bigdeli, \& Baines, 2020);

iv.) a more systemic and holistic approach to digital servitization. In particular, several papers in this special issue (Kamalaldin, Linde, Sjödin, \& Parida, 2020; Naik et al., 2020; Paiola \& Gebauer, 2020; Tronvoll, Sklyar, Sörhammar, \& Kowalkowski, 2020) suggest a need to extend the research scope from a single-firm or dyadic perspective to a network or ecosystem approach, and investigate how this changes the role of intermediate actors in the supply chain and their access to end customers;

v.) the mechanisms through which digital servitization leads to distinctive benefits, such as data monetization or sustainability. In particular, the papers in the special issue suggest addressing their linkages with exploration and exploitation capabilities, and considering how such benefits are connected to different degrees of actor relationships (Coreynen, Matthyssens, Vanderstraeten, \& Witteloostuijn, 2020; Kamaladin et al., 2020);

vi.) a more comprehensive analysis of the role of different digital technologies besides IoT, and of their combined effect. Several technologies have been underinvestigated to date, despite their potential impact on digital servitization (e.g. additive manufacturing, mixed reality, blockchain). Also, the tensions introduced by the adoption of different technologies at both intra- and interfirm levels should be investigated, to shed light on the risks of digital servitization initiatives (Tronvoll et al., 2020);

vii.) the role of digital technologies in shaping the evolutionary path of companies towards servitization stages and new business models.

In addition to these streams outlined in Paschou, Rapaccini, Adrodegari, and Saccani (2020), we suggest the following key aspects for the future agenda of academic inquiries.

\subsection{Relying on a variety of research strategies and methods}

The first key aspect on the agenda for future academic work is about relying on a range of research strategies and methods. While the increasing level of research output on digital servitization is encouraging, we believe that the emerging dominance of qualitative research points to a lack of theoretical development and validation. In the future, what is already known and what is being explored (i.e., the research questions) should drive the research strategy. Accordingly, nascent theories
- that is, research areas in the digital servitization domain where the research questions are of an exploratory nature - require interviews, case studies, and direct observation of the phenomena. Iterative exploratory content analysis of these types of data yields new constructs and suggestive models of correlation. Research propositions and provisional causal models, which constitute the expected contribution of intermediate theories, require explicit interview protocols, survey work and archival data to be processed via statistical analysis and pairwise comparisons. Moving toward a fully mature theory on digital servitization requires precise models that capture hypotheses generated by the same theory. To generate them, it is necessary to establish quantitative measures of established constructs on digital servitization and to test them statistically. Clearly, future research on digital servitization should not be dominated by qualitative research, but entail an adequate variety of research methods.

\subsection{Role of external growth for facilitating digital growth}

A second academic research avenue relates to the role of external growth for facilitating digital growth. Digital servitization is implicitly assumed to lead to new and combined digital and service capabilities, which, in turn, facilitate internal growth. A shortcoming of this assumption is that it neglects external growth. Yet, in addition to developing their own digital capabilities, product companies often acquire and partner with other companies specializing in digital technologies. Going back to our examples in Section 3, we found that Intel strengthened its AI capabilities and entered the market for autonomous driving through strategic acquisitions (e.g. Habana Labs and Mobileye). Intel is now able, for instance, to offer mobility-as-a-service for owners of vehicle fleets. Similarly, Voith also relied on a combination of external and internal capability developments to facilitate its digital transformation journey. Voith brought together its digital start-up activities under the umbrella of the business unit - Digital Ventures, which steers the development and management of potential new digital startup activities and acts as an incubator to drive forward new digital business models for the entire Voith Group. These include activities in markets not yet covered by Voith, as well as technology investments with a start-up character that have arisen through acquisitions or joint ventures. Typical illustrations are Voith's strategic cooperation with the Kudelski Group, a company specializing in digital security systems or Ray Sono, a leader in digital communication and interaction.

Such external growth and capability development might be considered interesting and important "anomalies" (Kuhn, 1970) to the current theoretical assumptions on internal growth, and the theoretical lenses and methodologies from the M\&A literature could be used to consider whether or not it may make economic sense to acquire specialized companies as a strategy for digital servitization.

\subsection{Competitive arena around IoT platforms}

A third future academic inquiry is about the new competitive arena emerging around IoT platforms in B2B markets. The platform revolution is now expanding into the business-to-business (B2B) space. Many product companies are currently investing in their own IoT platforms (e.g. Bosch's IoT Suite, General Electric's Predix, Siemens' Mindsphere, Honeywell's Lumada, Schneider's Ecostruxure) with similar or different purposes (Figure 3). However, previous platform studies have mostly concentrated on the $\mathrm{B} 2 \mathrm{C}$ context or marketplaces as a sub-category of platforms.

The term "platform" has become popular since the rapid success of digital pioneers such as Amazon, Alibaba, Facebook, Google, Uber etc. These companies pioneered marketplaces for enabling and supporting transactions between independent supply-and-demand side participants (Parker et al., 2016). However, such marketplaces are just one category of platforms (Gawer \& Cusumano, 2014; McIntyre \& Srinivasan, 2017; Täuscher \& Laudien, 2018, Ardolino, Eloranta, \& Saccani, 2020). 


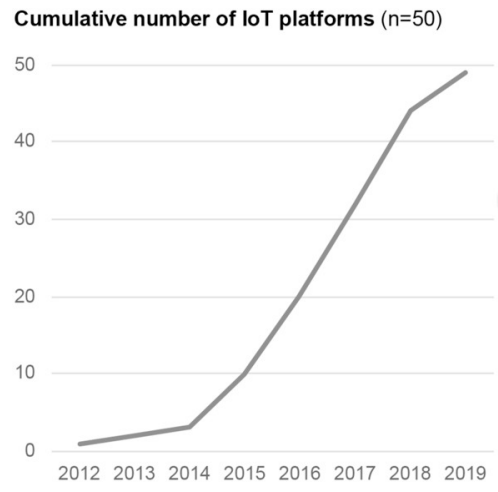

Year loT platform was launched
Value architecture

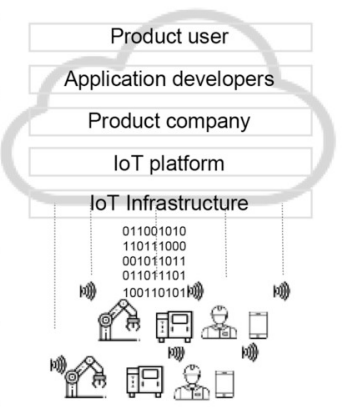

Platform architypes

Vertical platforms (e.g. aviation industry)

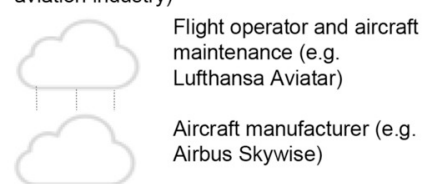

Component supplier (e.g GE Predix ${ }^{\mathrm{TM}}$
Horizontal platforms (e.g. automation industry)

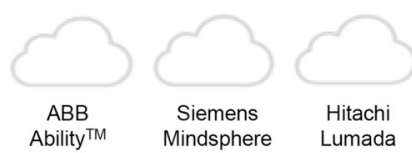

Fig. 3. IoT platforms.

An important insight into B2C platforms is that only a few companies dominate the ecosystem and tend to capture a disproportionate and expanding share of economic value. Accordingly, there have been numerous winner-takes-all examples, leading to a quasi-monopoly for search engines, online marketplaces, maps, music services etc. (Eisenmann, Parker, \& Van Alstyne, 2011). This disproportionate fraction of economic value results from the specific characteristics of B2C platforms (e.g. channeling the access to intangible assets, high development, but low implementation costs, revenue structures composed of subscription fees, advertisements, etc.), low cost of errors, positive network effects). B2C platforms have fundamentally changed and disrupted the existing competitive landscape in many B2C markets.

In order to remain competitive, product companies have begun to cooperate with infrastructure providers to build their own IoT platforms. But these providers are increasingly competing in hybrid valueadded activities that involve digital innovations (e.g. digital twins, artificial intelligence and machine learning etc.), which in turn open up new growth and differentiation potential. How IoT platforms contribute in the move towards digital servitization, and the dynamics of value creation and co-opetition among product companies and infrastructure services, are areas still open for investigation in the context of IoT platforms.

Moreover, future inquiries on platforms should start by describing the distinct characteristics of IoT platforms and address how these characteristics will influence the competitive landscape around IoT platforms. For instance, it has been argued that IoT platforms contribute to the path toward servitization, since they inherently provide mechanisms for complexity management that lead to an efficient and effective balance between standardization and customization in designing and delivering solutions (Ardolino, Saccani, Adrodegari, \& Perona, 2020). Such a role and its mechanisms deserve further investigation.

Finally, future research could look at the competitive arena around IoT platforms from a vertical and/or horizontal perspective. The horizontal perspective entails various IoT platforms in one specific valuecreation activity within the value network, whereas the vertical perspective would consider IoT platforms upstream and downstream within the value chain. The value architecture of an IoT platform and its corresponding competitive arena should be analyzed through the lenses of vertical and/or horizontal perspectives.

Overall, we hope that this introduction and all six articles in the special issue provide valuable new insights for academics and practitioners alike.

\section{References}

Ardolino, M., Eloranta, V., \& Saccani, N. (2020). Platforms and Complexity Management: An Exploration of the Digital Servitization Domain. accepted for publication. Ardolino, M., Saccani, N., Adrodegari, F., \& Perona, M. (2020). A business model framework to characterize digital multisided platforms. J. Open Innov. Technol. Mark. Complex. 6, 10.

Baines, T., Bigdeli, A. Z., Bustinza, O. F., Guang, V., Baldwin, J., \& Ridgway, K. (2017). Servitization : revisiting the state-of-the-art and research priorities. International Journal of Operations \& Production Management, 37(2), 256-278.

Baines, T. S., Lightfoot, H., Benedettini, O., \& Kay, J. M. (2009). The servitization of manufacturing: a review of literature and reflection on future challenges. Journal of Manufacturing Technology Management, Vol. 20(5), 547-567.

Baines, T. S., Lightfoot, H. W., Evans, S., Neely, A., Greenough, R., Peppard, J., ... Alcock, J. R. (2007). State-of-the-art in product-service systems. Proceedings of the Institution of Mechanical Engineers, Part B: Journal of Engineering Manufacture, 221(10), 1543-1552.

Brax, S. (2005). A manufacturer becoming service provider - Challenges and a paradox. Managing Service Quality, 15(2), 142-155.

Coreynen, W., Matthyssens, P., Vanderstraeten, J., \& van Witteloostuijn, A. (2020). Unravelling the internal and external drivers of digital servitization: A dynamic capabilities and contingency perspective on firm strategy. Industrial Marketing Management.

Cortimiglia, M. N., Ghezzi, A., \& Frank, A. G. (2016). Business model innovation and strategy making nexus: evidence from a cross-industry mixed-methods study. $R \& D$ Management, 46(3), 414-432.

Cusumano, M. A., Kahl, S. J., \& Suarez, F. F. (2015). Services, industry evolution, and the competitive strategies of product firms. Strategic Management Journal, 36(4), $559-575$.

Eisenmann, T., Parker, G., \& Van Alstyne, M. (2011). Platform envelopment. Strategic Management Journal, 32(12), 1270-1285.

Gawer, A., \& Cusumano, M. A. (2014). Industry platforms and ecosystem innovation. Journal of Product Innovation Management, 31(3), 417-433.

Gebauer, H. (2008). Identifying service strategies in product manufacturing companies by exploring environment - strategy configurations. Industrial Marketing Management, 37(3), 278-291.

Gebauer, H., Fleisch, E., \& Friedli, T. (2005). Overcoming the service paradox in manufacturing companies. European Management Journal, 23, 14-26.

Gebauer, H., Fleisch, E., Lamprecht, C., \& Wortmann, F. (2020). Growth paths for overcoming the digitalization paradox. Business Horizons, 63(3), 313-323.

General Electric (1995). Annual report. MA: GE.

General Electric (2005). Annual report. MA: GE.

General Electric (2015). Annual report. MA: GE.

General Electric (2018). Annual report. MA: GE.

IBM (1993). Annual report. Armonk, NY: IBM.

IBM (2005). Annual report. Armonk, NY: IBM.

IBM (2018). Annual report. Armonk, NY: IBM.

Kamalaldin, A., Linde, L., Sjödin, D., \& Parida, V. (2020). Transforming provider-customer relationships in digital servitization: A relational view on digitalization. Industrial Marketing Management.

Kastalli, I. V., \& Van Looy, B. (2013). Servitization: Disentangling the impact of service business model innovation on manufacturing firm performance. Journal of Operations Management, 31(4), 169-180.

Kowalkowski, C., Gebauer, H., \& Oliva, R. (2017). Service growth in product firms: Past, present, and future. Industrial Marketing Management, 60, 82-88.

Kuhn, T. S. (1970). The structure of scientific revolutions. Chicago: The University of Chicago Press.

Manjoo, F. (2017). How the Frightful Five Put Start-Ups in a Lose-Lose Situation. The New York Times, 18.

McIntyre, D. P., \& Srinivasan, A. (2017). Networks, platforms, and strategy: Emerging views and next steps. Strategic Management Journal, 38(1), 141-160.

Naik, P., Schroeder, A., Kapoor, K. K., Bigdeli, A. Z., \& Baines, T. (2020). Behind the scenes of digital servitization: Actualising IoT-enabled affordances. Industrial Marketing Management.

Neely, A. (2008). Exploring the financial consequences of the servitization of manufacturing. Operations Management Research, 1, 103-118. https://doi.org/10.1007/ s12063-009-0015-5.

OED online (2020). “digitalization", n.2. http://www.oed.com/view/Entry/24206 
accessed 31st Mar 2020

Paiola, M., \& Gebauer, H. (2020). Internet of things technologies, digital servitization and business model innovation in BtoB manufacturing firms. Industrial Marketing Management.

Parker, G. G., Van Alstyne, M. W., \& Choudary, S. P. (2016). Platform Revolution: How Networked Markets Are Transforming the Economy? and How to Make Them Work for You. WW Norton \& Company.

Paschou, T., Rapaccini, M., Adrodegari, F., \& Saccani, N. (2020). Digital servitization in manufacturing: A systematic literature review and research agenda. Industrial Marketing Management.

Porter, M. E., \& Heppelmann, J. E. (2014). How smart, connected products are transforming competition. Harvard Business Review, 92(11), 65-88.

Porter, M. E., \& Heppelmann, J. E. (2015). How smart, connected products are transforming companies. Harvard Business Review, 93(10), 96-114.

Rapaccini, M., \& Visintin, F. (2015). Devising hybrid solutions: an exploratory framework. Production Planning and Control, 26(8), 654-672.

Ross, J. W., Beath, C. M., \& Mocker, M. (2019). Creating digital offerings customers will buy. MIT Sloan Management Review, 61(1), 64-69.

Rust, R. T. (2004). If everything is service, why is this happening now, and what difference does it make. Journal of Marketing, 68(1), 23-24.

Schneider, P. (2018). Managerial challenges of Industry 4.0: an empirically backed research agenda for a nascent field. Review of Managerial Science, 12(3), 803-848.

Story, V. M., Raddats, C., Burton, J., Zolkiewski, J., \& Baines, T. (2017). Capabilities for advanced services: A multi-actor perspective. Industrial Marketing Management, 60, $54-68$.

Täuscher, K., \& Laudien, S. M. (2018). Understanding platform business models: A mixed methods study of marketplaces. European Management Journal, 36(3), 319-329.
Teece, D. J. (2010). Business models, business strategy, and innovation. Long Range Planning, 43(2/3) 172 e 194.

Tronvoll, B., Sklyar, A., Sörhammar, D., \& Kowalkowski, C. (2020). Transformational shifts through digital servitization. Industrial Marketing Management.

Tukker, A. (2004). Eight types of product-service system: eight ways to sustainability? Experiences from SusProNet. Business Strategy and the Environment, 13(4), 246-260.

Vendrell-Herrero, F., Bustinza, O. F., Parry, G., \& Georgantzis, N. (2017). Servitization, digitization and supply chain interdependency. Industrial Marketing Management, 60, $69-81$.

Voith (2018). Annual report 2017/2018. Germany:Voith.: Heidenheim.

Heiko Gebauer ${ }^{\mathrm{a}}$, Marco Paiola ${ }^{\mathrm{b}, *}$, Nicola Saccani $^{\mathrm{d}}$, Mario Rapaccini ${ }^{\mathrm{c}}$ a IMW - DataMining und Wertschöpfung, Germany Strategy and International Management, Linköping University, Sweden Universität St. Gallen, Neumarkt 9-19, 04109 Leipzig, Switzerland

${ }^{\mathrm{b}}$ Department of Economics and Management, University of Padua, via del Santo 33, 35123 Padova, Italy

${ }^{\mathrm{c}}$ Department of Industrial Engineering, University of Florence, V.le Morgagni 40, 50131 Florence, Italy

${ }^{\mathrm{d}}$ Department of Mechanical and Industrial Engineering, University of Brescia, Via Branze 38, 25123 Brescia, Italy E-mail address: marco.paiola@unipd.it (M. Paiola).

* Corresponding author. 